\title{
Chain length of dietary fatty acids determines gastrointestinal motility and visceromotor function in mice in a fatty acid binding protein 4-dependent manner
}

\author{
Paula Mosińska ${ }^{1} \cdot$ Adrian Szczepaniak $^{1} \cdot$ Tatiana Wojciechowicz $^{2} \cdot$ Marek Skrzypski $^{2} \cdot \mathrm{Krzysztof} \mathrm{Nowak}^{2}$. \\ Jakub Fichna'
}

Received: 21 December 2018 / Accepted: 19 September 2019 / Published online: 27 September 2019

(c) The Author(s) 2019

\begin{abstract}
Purpose We hypothesize that different types of dietary fatty acids (FAs) affect gastrointestinal (GI) motility and visceromotor function and that this effect can be regulated by the fatty acid binding protein 4 (FABP4).

Methods Mice were fed for 60 days with standard diet (STD), STD with 7\% (by weight) coconut oil, rich in medium-chain FAs (MCFAs) (COCO), or with 7\% evening primrose oil, rich in long-chain FAs (LCFAs) (EPO). In each group, half of the mice received FABP4 inhibitor, BMS309403 (1 mg/kg; i.p.) twice a week. Body weight (BW) and food intake were measured; well-established tests were performed to characterize the changes in GI motility and visceral pain. White adipose tissue and colonic samples were collected for cell culturing and molecular studies.

Results COCO significantly increased GI transit, but not colonic motility. COCO and EPO delayed the onset of diarrhea, but none affected the effect of loperamide. EPO reduced BW and increased the visceromotor response (VMR) to colorectal distension (CRD). COCO and EPO reduced differentiation of preadipocytes. Treatment with BMS309403: (1) reversed the effects induced by COCO in physiological conditions and in mouse models of diarrhea; (2) prevented the effects of EPO on BW, VMR to CRD and castor oil-induced diarrhea; (3) affected proliferation of preadipocytes; (4) changed the expression of Fabp4 in colonic and adipocyte samples from COCO and EPO.

Conclusion Modifying dietary intake of MCFAs and LCFAs may be used to control GI motility or visceral pain and thus modulate the symptoms of functional GI disorders. The effect is dependent on the expression of FABP4.
\end{abstract}

Keywords Medium-chain fatty acids $\cdot$ Long-chain fatty acids $\cdot$ Coconut oil $\cdot$ Fatty acid binding protein $4 \cdot$ Gastrointestinal motility $\cdot$ Irritable bowel syndrome

\begin{tabular}{|c|c|c|c|c|}
\hline \multicolumn{3}{|c|}{ Abbreviations } & FAs & Fatty acids \\
\hline \multicolumn{2}{|c|}{ CLA } & Conjugated LA & FABP4 & Fatty acid binding protein 4 \\
\hline \multicolumn{2}{|c|}{$\mathrm{COCO}$} & Coconut oil & FGIDs & Functional gastrointestinal disorders \\
\hline \multicolumn{2}{|c|}{$\mathrm{Ct}$} & Threshold cycle & FODMAP & Fermentable oligo-, di-, monosaccharides and \\
\hline \multicolumn{2}{|c|}{ DMSO } & Dimethyl sulfoxide & & polyols \\
\hline \multirow{2}{*}{\multicolumn{2}{|c|}{ EPO }} & Evening primrose oil & FPO & Fecal pellet output \\
\hline & & & i.p. & Intraperitoneal \\
\hline \multirow{3}{*}{\multicolumn{3}{|c|}{$\begin{array}{l}\text { Electronic supplementary material The online version of this } \\
\text { article (https://doi.org/10.1007/s00394-019-02094-2) contains } \\
\text { supplementary material, which is available to authorized users. }\end{array}$}} & KRBH & Krebs-Ringer HEPES buffer \\
\hline & & & IBS & Irritable bowel syndrome \\
\hline & & & IBS-A & Alternating IBS \\
\hline & Jakul & & IDs-c & Constipation-predominant \\
\hline & jakuk & onumed lodz nl & IDS-D & Diarrhea-predominant IBS \\
\hline & & & LA & Linoleic acid \\
\hline \multirow[t]{2}{*}{1} & Depa & ent of Biochemistry, Faculty of Medicine, Medical & LCFAs & Long-chain fatty acids \\
\hline & Univ & y of Lodz, Mazowiecka 6/8, 92-215 Lodz, Poland & MCFAs & Medium-chain fatty acids \\
\hline \multirow[t]{2}{*}{2} & Depa & it of Animal Physiology and & PUFAs & Polyunsaturated fatty acids \\
\hline & Univ & y of Life Sciences, Poznan, Poland & RT & Room temperature \\
\hline
\end{tabular}


STD

VMR

Standard laboratory diet

WAT

Visceromotor response

White adipose tissue

\section{Introduction}

Functional gastrointestinal disorders (FGIDs) are a heterogeneous group of chronic conditions that considerably reduce the patient's quality of living, interfering with their social life, education and working ability. The most common FGID noted in the population worldwide is irritable bowel syndrome (IBS) [1], whose prevalence in Europe and North America ranges from 10 to 20\% [2-4]. According to the symptom-based classification system (the Rome IV criteria), IBS is a chronic, relapsing bowel disorder associated with the following symptoms: stool irregularities, visceral hypersensitivity, altered mucosal function with concomitant psychiatric and somatic comorbidities [5]. Depending on patterns of symptoms, IBS is classified as IBS-C (constipation-predominant), IBS-D (diarrhea-predominant) or IBS-A (alternating, including both diarrhea and constipation); however, the symptoms may vary and oscillate not only between subtypes but also within the same patient over time. Due to the complex nature of IBS and only a partially understood pathogenesis, this condition still poses an immense challenge in the twenty-first century for both general practitioners and clinicians.

Ingestion of food components has long been linked with IBS symptoms. At least two-thirds of IBS patients reported food as an important trigger for worsening their condition [6] and thus, many of them avoid certain dietary components. Due to the fact that food is a complex milieu of several chemicals, it is hard to pinpoint one particular group or type of nutrient responsible for the onset or worsening of symptoms. In the recent years, clinicians have suggested that the reduction of fiber intake or the consumption of fermentable oligo-, di-, monosaccharides and polyols (FODMAP) may minimise the occurrence of symptoms [7-10].

There are little data addressing the lipid turnover in IBS [2, 11-14]. Park et al. [15] showed in rats that dietary fats attenuated the motile function of the entire GI tract and delayed gastroduodenal transit. Available data evaluating dietary fat intake between IBS patients and control individuals are inconsistent, yet it undoubtedly indicates a disturbed level of several fatty acids (FAs) in their serum. For example, Clarke et al. [16] reported increased concentrations of n-3 polyunsaturated fatty acids (PUFAs) in the serum of IBS patients, compared to the control group. In contrast, Solakivi et al. [17] showed that the proportions of arachidonic acid and the FAs belonging to the family of PUFAs were significantly decreased in subjects with IBS, compared to controls. Of note, the same study highlighted that IBS group had higher concentrations of unsaturated and monounsaturated FAs, and lower concentrations of n-3 PUFA, compared to controls. There were also attempts to assess the effects of administering lipids to IBS subjects. A study by Caldarella et al. [12] showed that intraduodenal lipid infusion of a low-calorie fatty meal decreased the rectal sensory threshold in comparable fashion in both IBS-C and IBS-D. Another study documented changes in the pattern of viscerosomatic pain referral in IBS patients and increased their sensitivity for gas sensation and perception of urge [13]. Although the enhancement of intestinal sensitivity occurred independent of the type of IBS, gender or psychological factors, the mechanism behind it remains uncertain.

Several studies have suggested the involvement of selected proteins secreted by the white adipose tissue (WAT) in the pathophysiology of IBS [18-20]. Fatty acid binding protein 4 (FABP4) is predominantly present in adipocytes, where it is able to bind to hydrophobic ligands, including eicosanoids, saturated and unsaturated FAs, and participate in their metabolism and excretion from the body. It has been recently shown that mouse and human gut epithelial Paneth cells express FABP4 and are simultaneously the main source of its presence in the intestines [21].

Our previous studies showed that the mRNA expression of FABP4 was significantly decreased in colonic samples of IBS-C patients, when compared to the control group indicating the active contribution of the protein in the course of IBS [22]. We also demonstrated that the acute administration of the FABP4 inhibitor, BMS309403, increased motility in the mouse lower GI tract in physiological conditions and in pharmacologically delayed GI transit.

Since the function of the lower digestive tract can be affected by ingestion of FAs, we aimed to determine the effects of dietary FAs on the lower GI motility and visceral pain. We also verified whether the FABP4 pathway is in charge of the effects observed by the implementation of dietary modifications. Finally, to better understand the role of FABP4 in the lipid turnover, we characterized the effects of treatments on adipocyte differentiation and proliferation.

\section{Materials and methods}

\section{Animals and study design}

Experimentally naive male BALB/c mice, weighing 22-24 g were obtained from the vivarium at the University of Lodz, Poland. The animals were housed under controlled laboratory conditions $\left(22-23{ }^{\circ} \mathrm{C}\right.$, relative humidity: $45-55 \%$, 12:12 h light/dark cycle, lights on at 6:00 a.m.) in sawdustlined plastic cages. Tap water was available ad libitum. To minimize circadian influence, all experiments were performed between 7:00 $\mathrm{h}$ and 16:00 $\mathrm{h}$ after at least 7 days of 
acclimatization. After acclimatization, the weight-matched animals were randomly assigned to three groups fed, respectively, with standard laboratory diet (STD) containing 7\% fat by weight, diet supplemented with $7 \%$ coconut oil, rich in medium-chain FAs (MCFAs) (COCO), or diet supplemented with $7 \%$ evening primrose oil, rich in long-chain FAs (LCFAs) (EPO). COCO group resulted in a diet rich mostly in lauric and myristic FAs, whereas EPO enrichment results in a diet with high content of linoleic acid. Animals were fed for 60 days with free access to water. All diets were formulated to meet the nutritional requirements of growing mice and manufactured by the external company specialized in animal food supply (ZooLab, Poland) (Table 1) [23]. Body weight was measured twice a week; the food intake was monitored every day in the morning between 7 and 8 a.m. Experimental groups comprised 5-10 animals to provide statistically relevant data.

Two parallel studies were performed:

1. Mice $(n=72)$ were randomly allocated to three diet groups (STD, COCO or EPO, 24 mice/group) and fed for 60 days. Animals were subsequently used to assess the GI motility in physiological conditions i.e. colon bead expulsion test and fecal pellet output (FPO) and under pathophysiological conditions, i.e. mouse models mimicking constipation and diarrhea. Twelve animals in each dietary intervention received the intraperitoneal (i.p.) injection of the FABP4 inhibitor, BMS309403 $(1 \mathrm{mg} / \mathrm{kg})$ twice a week [22]. The experiments were performed in two-day intervals.

2. Mice $(n=60)$ were randomly allocated to three diet groups (STD, COCO or EPO, 20 mice/group) and fed for 60 days. Ten animals in each group were additionally administered with BMS309403 (1 mg/kg, i.p.) twice a week. Subsequently, the colorectal distention (CRD) was performed to determine the visceromotor response (VMR) to pain.

A schematic representation of the experiments included in the study is shown in Fig. 1.

The experimental protocols followed the European Communities Council Directive of 22 September 2010 (2010/63/ EU), were in accordance with Polish legislation on animal experimentations, and were approved by the Local Ethics Committee at the Medical University of Lodz (\#63/ LB77/2017). All efforts were made to minimize animal suffering and to reduce the number of animals used.

BMS309403 and loperamide were dissolved in 5\% dimethyl sulfoxide (DMSO) and diluted in $0.9 \%$ saline to desired concentrations as selected in preliminary studies. 5\% DMSO dissolved in $0.9 \%$ saline was used as vehicle. BMS309403 was injected intraperitoneally (i.p.) at the dose of $1 \mathrm{mg} \mathrm{kg}^{-1}$ twice a week for 60 days. For mouse models mimicking IBS, loperamide or castor oil was administered acutely at the dose of $3 \mathrm{mg} \mathrm{kg}^{-1}$ (i.p., $100 \mu \mathrm{L} /$ mouse) and $0.2 \mathrm{~mL} /$ mouse per os (p.o.), respectively, $15 \mathrm{~min}$ and $10 \mathrm{~min}$ before the respective experiment. Control animals received vehicle alone $(100 \mu \mathrm{L} /$ mouse, i.p.). The vehicles in the used concentrations had no effect on the observed parameters in mice. Mice used in VMR to CRD were anesthetized by the i.p. injection of ketamine/xylazine solution $1 \mathrm{~mL}$ and $0.5 \mathrm{~mL}$, respectively, diluted in $8.5 \mathrm{~mL}$ of $0.9 \%$ sodium chloride.
Table 1 Composition of diets that will be included in the study

\begin{tabular}{llll}
\hline Ingredients (g/kg diet) & STD & $\begin{array}{l}\text { STD supplemented with } \\
7 \% \text { coconut oil (COCO) }\end{array}$ & $\begin{array}{l}\text { STD supplemented with 7\% } \\
\text { evening primrose oil (EPO) }\end{array}$ \\
\hline Corn starch & 397.486 & 397.486 & 397.486 \\
Casein & 200.0 & 200.0 & 200.0 \\
Maltodextrin & 132.00 & 132.00 & 132.00 \\
Soybean oil & 70.00 & 0.00 & 0.00 \\
Coconut oil/evening primrose oil & 0.0 & 70.00 & 70.00 \\
Fiber & 50.00 & 50.00 & 50.00 \\
${ }^{a}$ AIN93G mineral mix & 35.00 & 35.00 & 35.00 \\
aAIN93G vitamin mix & 10.00 & 10.00 & 10.00 \\
L-Cystine & 3.00 & 3.00 & 3.00 \\
Choline bitartrate & 2.50 & 2.50 & 2.50 \\
Tert-butylohydrochinon & 0.014 & 0.014 & 0.014 \\
& 1000.0 & 1000.0 & 1000.0 \\
\hline
\end{tabular}

Full ingredient list for the diets in this study, formulated by ZooLab, Poland

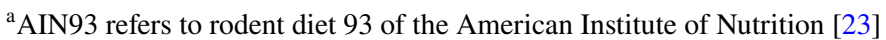




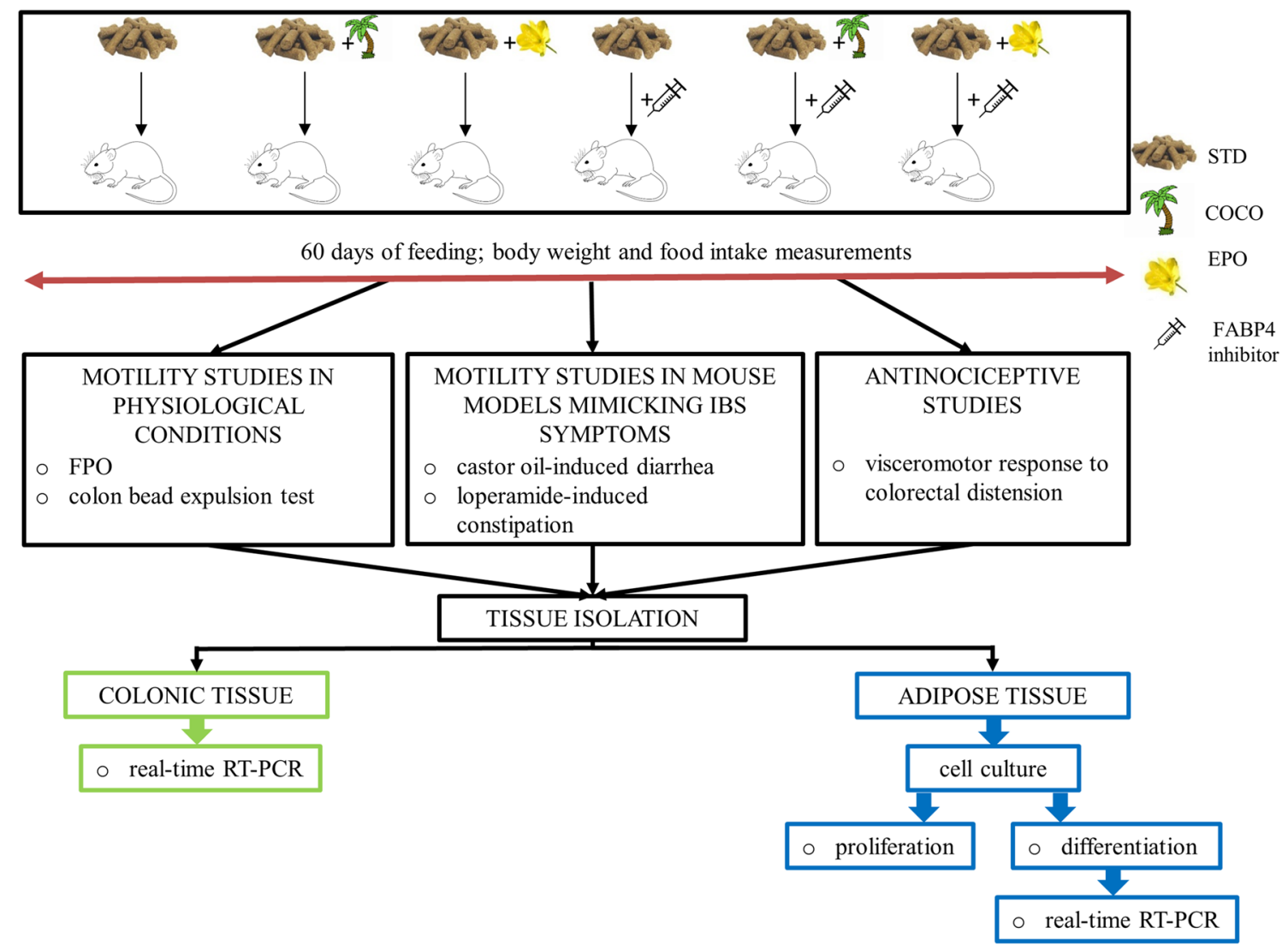

Fig. 1 Schematic representation of the experiments described in the paper

\section{Materials}

All drugs and reagents were purchased from Sigma-Aldrich (Poznań, Poland), unless stated otherwise. BMS309403, a FABP4 inhibitor, and loperamide were purchased from Tocris (Bristol, UK). Xylazine and ketamine were acquired from Biovet (Puławy, Poland). Isoflurane was obtained from Baxter Healthcare Corp. (IL, USA). PBS, in the form of readyto-use tablets, was purchased from Polgen (Lodz, Poland). TRIsure was obtained from Bioline (London, UK). The PCR TaqMan Gene Expression Assay probes used for the quantification of FABP4 mRNA expression were purchased from Life Technologies (CA, USA). Dulbecco's modified Eagle's medium Nutrient Mixture F-12 (DMEM/F12) for cell culture was obtained from Thermo Fisher Scientific, Inc. (Waltham, USA).

\section{Gastrointestinal motility studies}

\section{Physiological conditions}

To measure whole GI transit, the fecal pellet output (FPO) was assessed in non-fasted animals [24] after 60 days of feeding. Mice were placed individually into clean transparent cages with no access to water or chow. Sixty minutes later, the number of excreted fecal pellets was counted as a measure of GI tract motility.

To measure colonic motility, distal colonic bead expulsion test was performed after 60 days of feeding following an overnight fasting (for $16 \mathrm{~h}$ ) with free access to drinking water, as described previously [24]. On the day of the experiment, a prewarmed $\left(37^{\circ} \mathrm{C}\right)$ glass bead $(2 \mathrm{~mm})$ was inserted $2 \mathrm{~cm}$ into the distal colon using a silicone pusher under light isoflurane anesthesia. After bead insertion, mice were separated into transparent, individual cages and the time to bead expulsion was measured up to 15 min after administration of BMS309403 or control vehicle [25].

\section{Pathophysiological conditions}

Constipation was induced by the i.p. administration of peripherally restricted mu-opioid receptor agonist, loperamide, 15 min before the FPO test [26].

Diarrhea was induced by oral administration of castor oil as previously described by Fichna et al. [27]. Immediately after the castor oil administration, the animals were placed into individual wire-bottomed cages. The symptoms of diarrhea were evaluated depending on time between the 
administration of castor oil and diarrhea-related symptoms, i.e., excretion of liquid feces [28].

The effects of chronic administration (twice a week for 60 days) of BMS309403 on the GI motility were compared with the mean transit observed in the control (STD + BMS) group.

\section{Cell studies}

\section{Isolation of mouse white preadipocytes}

Primary adipocytes were isolated from epididymal fat pads from male BalbC mice, according to the methods by Skrzypski et al. [29] and Chatteryee et al. [30] with few modifications. The collected adipose tissue was purified from blood vessels and washed three times in sterile Krebs-Ringer buffer [118 mM NaCl, $1.3 \mathrm{mM} \mathrm{CaCl}_{2}, 4.8 \mathrm{mM} \mathrm{KCl}, 1.2 \mathrm{mM}$ $\mathrm{MgSO}_{4}, 1.2 \mathrm{mM} \mathrm{KH} \mathrm{PO}_{4}, 24.8 \mathrm{mM} \mathrm{NaHCO}{ }_{3}, 10 \mathrm{mM}$ HEPES 4-(2-hydroxyethyl)-1-pipera-zineethanesulfonic acid] supplemented with $3 \%$ bovine serum albumin, antibiotics $(100 \mathrm{U} / \mathrm{mL}$ penicillin and $0.1 \mathrm{mg} / \mathrm{mL}$ streptomycin) and $5 \mathrm{mM}$ glucose. The washed tissue was minced with scissors. The adipose tissues isolated from each mouse belonging to the same experimental group were pooled together. Thereafter, pooled tissues were digested in Krebs-Ringer HEPES buffer (KRBH) containing collagenase type II ( $3 \mathrm{mg} / \mathrm{mL})$, BSA, streptomycin and glucose $(5 \mathrm{mmol} / \mathrm{l})$ for $45 \mathrm{~min}$ at $37^{\circ} \mathrm{C}$ in a shaking water bath. After the incubation, growth medium containing $10 \%$ fetal bovine serum, penicillin and streptomycin was added to the flask. After digestion, lysate was centrifuged at $450 \times g$ for $10 \mathrm{~min}$ at room temperature (RT). To lyse the erythrocytes, the Red Blood Cell Lysing buffer (Sigma-Aldrich) was added to pellet. To discard the remaining undigested tissue debris, cells were filtered through a nylon mesh $(100 \mu \mathrm{m})$. Next, cells were filtered through a $40-\mu \mathrm{m}$ mesh. Filtered cells were centrifuged at $450 \times g$ to separate floating adipocytes from stromal-vascular cell pellets. The suspension containing mature adipocytes was discarded. The cell pellet was resuspended in DMEM/ F12 containing antibiotics and $10 \%$ fetal bovine serum and counted using a Fuchs-Rosenthal counter chamber with $0.4 \%$ trypan blue (cell viability $>95 \%$ ). Cells were seeded in multi-well plates and incubated under humified atmosphere $\left(5 \% \mathrm{CO}_{2}\right.$ and $95 \%$ air).

\section{Cell proliferation}

Cell proliferation was assessed using a cell proliferation ELISA BrdU colorimetric kit (Sigma-Aldrich). Isolated mouse preadipocytes were seeded in 96 -well plates and cultured for $24 \mathrm{~h}$. Cell culture was conducted at $37{ }^{\circ} \mathrm{C}$ in a humidified atmosphere (95\% air with $5 \% \mathrm{CO}_{2}$ ). Cells were deprived of serum for $24 \mathrm{~h}$ to synchronize the cell cycle.
Subsequently, $10 \mu \mathrm{L}$ of $10 \mu \mathrm{M}$ BrdU solution was added and incubated with cells for $2.5 \mathrm{~h}$. The incorporation of BrdU into DNA was measured colorimetrically using Cell Proliferation ELISA BrdU colorimetric kit (Roche Diagnostic, Penzberg, Germany) according to manufacturer protocol ending with colorimetric measurement at $450 \mathrm{~nm}$.

\section{Cell differentiation}

Differentiation of preadipocytes into adipocytes was induced by DMDM/F12 medium containing adipogenesis-promoting agents ( $2 \mathrm{nM}$ triiodothyronine, $167 \mathrm{nM}$ insulin and $30 \mathrm{nM}$ dexamethasone), according to the standard protocol [31]. The effect of differentiation on adipocytes was determined on days 1, 3 and 6. Successful differentiation was assessed by morphology of cells and compared with standard marker of Fabp 4 [32]. Cells were harvested at the days 1, 3 and 6 and stored at $-80^{\circ} \mathrm{C}$ in TRIsure reagent (Roche Diagnostics, Basel, Switzerland) for RNA extraction.

\section{Visceromotor response (VMR) to colorectal distension (CRD)}

The method used to evoke the model of visceral pain was performed as previously described [27]. Mice were anesthetized with ketamine/xylazine solution and underwent the surgery: two electrode wires were implanted into the abdominal oblique muscles. The ends of wires were pulled under the skin toward the incision on the neck and externalized. Incisions on neck and abdomen were tightly sutured; the ends of electrodes were mounted to the mouse's skin using stitches and tapes. All surgical procedures were carried out in line with the antiseptic policy according to the approved animal protocol guidelines. Animals were allowed to rest for 2 days in individual cages. The measurement of VMR to the pressure stimulus was conducted on day 3 . Each mouse was placed in a restraint to allow easy access to the tips of wires. Fogarty's catheter (Thru-lumen embolectomy catheter, Fogarty, Edwards Lifescience, Warsaw, Poland) was used to induce the pressure in the large intestine. Lubricated balloon end of catheter was inserted $5 \mathrm{~mm}$ proximal to the anus and taped to the tail. A reference electrode was attached to the mouse tail and all electrodes were placed in the appropriate plugs. VMR to four values of pressure was measured: $15 \mathrm{mmHg}, 30 \mathrm{mmHg}, 45 \mathrm{mmHg}$ and $60 \mathrm{mmHg}$ acquired by incrementally insufflating the balloon with distilled water $(0.2 \mathrm{~mL}, 0.4 \mathrm{~mL}, 0.6 \mathrm{~mL} 0.8 \mathrm{~mL}$, accordingly) for $10 \mathrm{~s}$ with 5 -min intervals. The 10-s stimulus was applied only once per pressure value. Electromyograms were acquired using Bio Amp (ADInstruments, Poznan, Poland), connected to PowerLab and a personal computer with Lab Chart 7 software. Electromyogram amplitudes in millivolts $(\mathrm{mV})$ were collected over the period of $10 \mathrm{~s}$ for the baseline (before the 
stimulus) and for the response to stimulus. Data are presented as the difference between the VMR induced by the distension and the baseline, expressed as the area under the curve.

\section{Quantitative analysis of FABP4}

\section{Mouse colonic tissue preparation}

The segments from the distal colon of each animal were resected. Fecal contents, as well as connective tissue residues were gently removed and rinsed with phosphate-buffered saline (PBS). Colon samples were transferred into new tubes and stored at $-80{ }^{\circ} \mathrm{C}$ until protein analysis.

\section{Quantification of FABP4 mRNA expression in mouse tissue and harvested cells}

For the quantification of mRNA expression, we applied the real-time fluorescence detection PCR method with FAM dyelabeled TaqMan probes (Applied, Biosystems, USA). The colonic mouse RNA was isolated according to the manufacturer's protocol using Total RNA Mini kit (A\&A Biotechnology, Poland). Briefly, colonic tissue samples were homogenized in TRIsure reagent (Bioline, London, UK) using an ultrasound homogenizer (Bandelin Sonoplus HD3100, Berlin, Germany), whereas harvested differentiated cells (pellet cells) were lysed with TRIsure and the cell lysate was further homogenized by passing cells through an insulin syringe three times. Subsequently, all samples were centrifuged $(11,000 \times g$ for $10 \mathrm{~min}$ at $4{ }^{\circ} \mathrm{C}$ ), placed onto silica columns and purified. Total RNA was eluted using diethyl pyrocarbonate treated water. The purity and quantity of the isolated RNA were measured using dedicated spectrophotometer (iMarkTM, BioRad Laboratories). The sample was characterized with A260 nm/A280 nm ratio, which was in the range of 1.79-2.01. Total RNA was then transcribed into cDNA with Maxima First Strand cDNA synthesis kit (Fermentas, Canada) with the following threestep incubation: $25^{\circ} \mathrm{C}$ for $10 \mathrm{~min}, 50{ }^{\circ} \mathrm{C}$ for $15 \mathrm{~min}$ and $85^{\circ} \mathrm{C}$ for $5 \mathrm{~min}$. Quantitative analysis was performed using fluorescently labeled TaqMan probes for mouse Fabp4 and for mouse hypoxanthine-guanine phosphoribosyltransferase 1 ( Hprtl) as endogenous control (Life Technologies, Carlsband, CA, USA) on Mastercycler S realplex 4 apparatus (Eppendorf, Germany) and TaqMan Gene Expression Master Mix (Life Technologies, Carlsbad, CA, USA) in accordance with the manufacturer's protocol. The catalog numbers for the probes used are as follows: FABP4-Mm00445878_m1, HPRT1Mm01545399_m1. The real-time reaction mixture was prepared in a total volume of $20 \mu \mathrm{L}$ and consisted of $1 \mu \mathrm{L}$ of cDNA, $10 \mu \mathrm{L}$ of TaqMan Gene Expression Master Mix, $8 \mu \mathrm{L}$ of RNA-free water and $1 \mu \mathrm{L}$ of FAM dye-labeled TaqMan probes. All experiments were performed in triplicate. The threshold cycle $(\mathrm{Ct})$ values for studied genes were normalized to $\mathrm{Ct}$ values obtained for a housekeeping gene, Hprtl. The relative expression levels were normalized to Hprtl and calculated as $2^{\wedge}\left[-\left(\mathrm{Ct}_{\mathrm{FABP} 4}-\mathrm{Ct}_{\mathrm{HPRT} 1}\right)\right] \times 1000$ [33].

\section{Statistical analysis}

Statistical analysis and curve-fitting were performed using Prism 5.0 (GraphPad Software Inc., La Jolla, CA, USA). The data are expressed as mean \pm SEM. One-way ANOVA followed by the Student-Newman-Keuls post hoc test was used for analysis of multiple treatment means. $p$ values $<0.05$ were considered statistically significant. The data and statistical analysis comply with the recommendations on experimental design and analysis in pharmacology [34].

\section{Results}

\section{Long-term dietary supplementation with evening primrose oil significantly changed the body weight of mice}

As shown in Fig. 2a, the animals fed with EPO presented with the lowest body weight gain after 60 days of feeding. The change was noticeable from the first day of feeding and maintained during the whole dietary intervention period. Significant differences were observed between EPO and STD groups as well as between EPO and the COCO groups, particularly between the 30th and 36th, 46th and 53rd and the 60th days of treatment $(p<0.05)$. In contrast, supplementation with coconut oil (COCO group) did not change the body weight of animals and showed comparable values with STD group.

To determine the possible mechanism responsible for the observed changes in body weight of animals from $\mathrm{COCO}$ and EPO groups, half of the animals were additionally injected with BMS309403, the FABP4 inhibitor at the dose of $1 \mathrm{mg} / \mathrm{kg}$ (i.p.). BMS309403, administered twice a week for 60 days, slightly reduced the body weight in $\mathrm{COCO}+\mathrm{BMS}$; although, this was not significant. No changes in the body weight were observed in the EPO + BMS group, when compared to STD + BMS group. However, a significant increase in the body weight in EPO+ BMS group vs. EPO group was noted in 32nd, 46th, 50th, 53rd and 60th days of dietary intervention $(p<0.05)$.

\section{Long-term dietary supplementation with coconut oil or evening primrose oil did not affect food intake in mice}

We did not observe any significant differences in the cumulative food intake between STD, COCO and EPO groups exposed to 60 days of feeding (Fig. 2b). In contrast, animals 
Fig. 2 Representative graphs for body weight changes (a) and food intake (b) in mice fed with standard diet (STD), standard diet supplemented with coconut oil (COCO) and standard diet supplemented with evening primrose oil (EPO) with and without treatment with BMS309403 (1 mg/kg; i.p.). Data represent mean \pm SEM of $n=10$ mice per group. ${ }^{*} p<0.05$ and $* * p<0.01$ vs. STD $;{ }^{\$} p<0.05,{ }^{\$} \$ p<0.01$ and ${ }^{\$ \$} p<0.001$ vs. STD with BMS309403; ${ }^{\#} p<0.05$ and ${ }^{\# \#} p<0.01$ vs. respective dietary intervention without BMS309403 (one-way ANOVA followed by post hoc NewmanKeuls multiple comparison test)

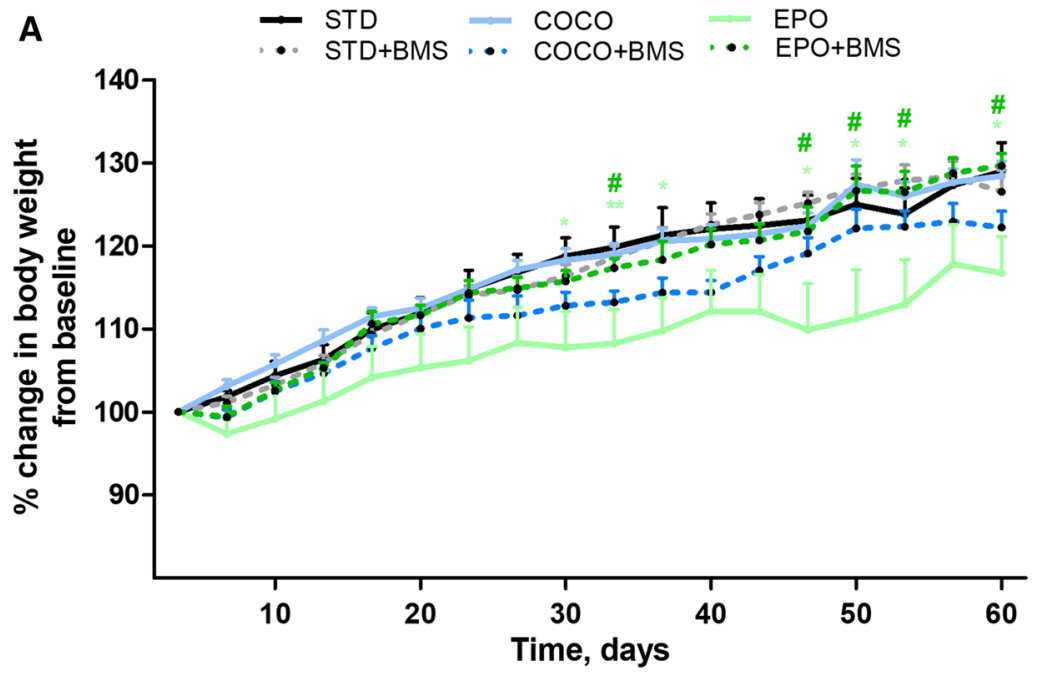

B

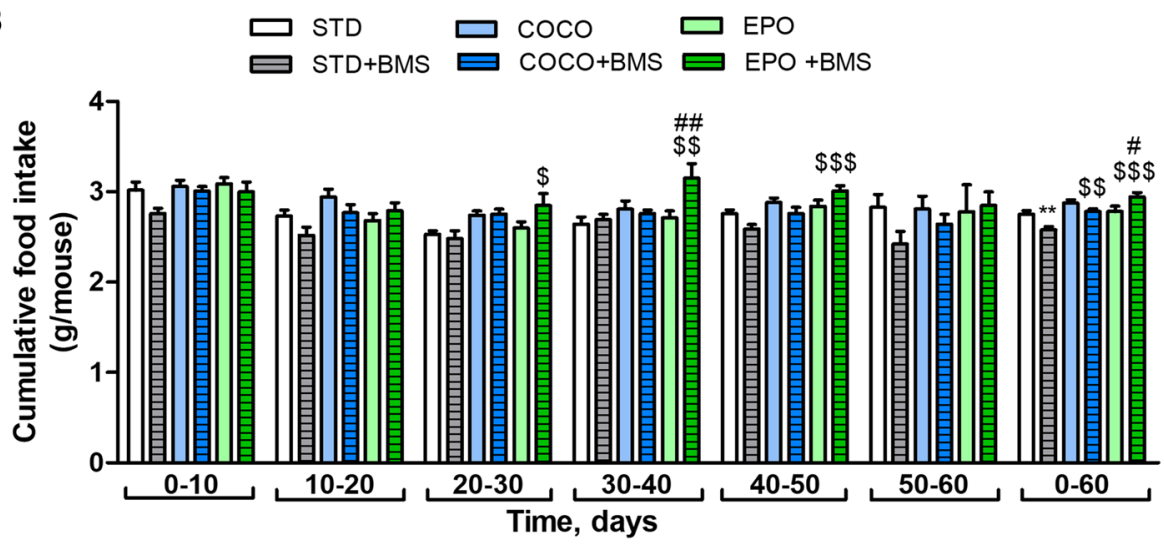

from the STD + BMS group ingested significantly less than those from STD $(p<0.01)$, whereas the animals fed with $\mathrm{EPO}+\mathrm{BMS}$ - significantly more than those on EPO diet $(p<0.05)$. No difference between the $\mathrm{COCO}+\mathrm{BMS}$ and COCO groups was noted (Fig. 2b).

Mice from EPO + BMS group consumed more of their meal compared to BMS309403-treated animals being on the STD diet (STD + BMS group). A significant increase was first observed from the 30th day of feeding $(p<0.05)$ and continued until the 50th day $(p<0.001)$. The treatment with BMS309403 also increased the average cumulative food intake (0-60 days) in $\mathrm{COCO}+\mathrm{BMS}$ and $\mathrm{EPO}+\mathrm{BMS}$ groups $(p<0.01$ and $p<0.001$ vs. STD + BMS group, respectively).

\section{Diet supplemented with the coconut oil significantly increased mouse GI transit and BMS309403 administration reversed this effect}

FPO was used to verify the effects of supplementation with $\mathrm{COCO}$ and EPO on mouse GI transit. In the COCO group, the GI transit was accelerated in mice under physiological conditions, resulting in a significant increase in the number of pellets excreted over $60 \mathrm{~min}$ ( $p<0.05$ vs. animals fed with standard diet, STD) (Fig. 3a). In contrast, the defecation pattern of mice fed with EPO diet did not change when compared to animals on STD diet.

Chronic administration of the selective FABP4 inhibitor, BMS309403, at the dose of $1 \mathrm{mg} / \mathrm{kg}$ (i.p.) delayed the $\mathrm{GI}$ transit in $\mathrm{COCO}+\mathrm{BMS}$ group. The intestinal motor activity in the STD + BMS and EPO + BMS groups was similar to the respective dietary modifications without the BMS309403 intervention (animals belonging to EPO and STD, respectively) (Fig. 3a).

\section{Dietary supplementation with coconut oil or evening primrose oil had no effect on the mouse colonic transit in physiological conditions}

To characterize the effects of each diet (STD, COCO and EPO) on colonic motor function, we performed the colonic bead expulsion test. None of the diets produced significant changes in the colonic motility (Fig. 3b).

The i.p. injection of BMS309403 in STD + BMS and $\mathrm{COCO}+\mathrm{BMS}$ groups prolonged the time to bead expulsion, reflecting a significant inhibitory effect on propulsive motility in the lower GI tract ( $p<0.001$ vs. STD and $p<0.05$ vs. 

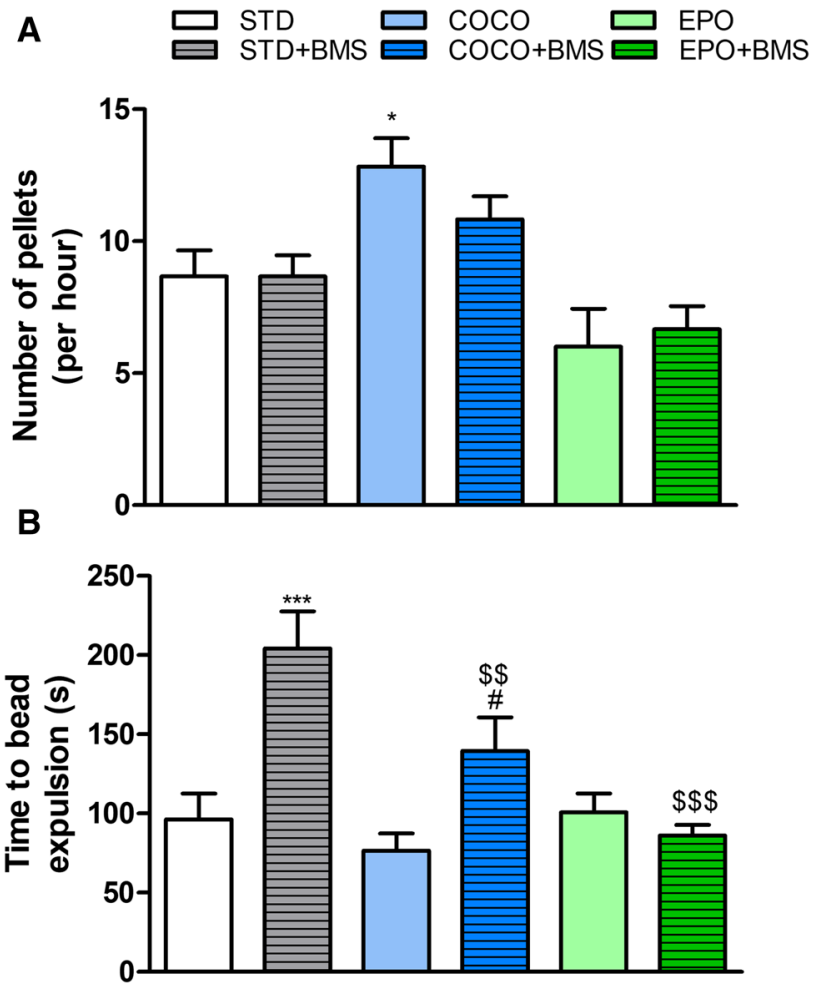

Fig. 3 The effect of different dietary interventions (STD, COCO and EPO) with or without the administration of BMS309403 (1 mg/ $\mathrm{kg}$, i.p.) on fecal pellet output (a) and colonic transit in mice (b). Data represent mean \pm SEM of $n=5-6$ mice per group. ${ }^{*} p<0.05$, $* * * p<0.001$ vs. STD; $\$ p<0.01$ and $\$ \$ p<0.001$, vs. STD with BMS309403; ${ }^{\#} p<0.05$ vs. respective dietary intervention without BMS309403 (one-way ANOVA followed by post hoc NewmanKeuls multiple comparison test)

COCO, respectively) (Fig. 3b). Colonic motility pattern in the EPO + BMS group did not change after the injection of FABP4 inhibitor compared to the EPO group.

\section{Chronic administration of BMS309403 to mice fed with coconut oil significantly reversed loperamide-induced hypomotility}

Effects of dietary supplementations and the FABP4 inhibitor, BMS309403, on the GI motility were also assessed in the mouse model mimicking constipation.

We verified whether the effect induced by loperamide could be reversed by either dietary modification or administration of the BMS309403. We observed that in all experimental groups (STD, STD + BMS, $\mathrm{COCO}, \mathrm{COCO}+\mathrm{BMS}$, $\mathrm{EPO}$ and $\mathrm{EPO}+\mathrm{BMS})$ loperamide, an opioid anti-diarrheal agent, significantly inhibited the GI motility ( $p<0.001$ vs. STD or STD + BMS groups, not injected with loperamide) (Fig. 4a). Dietary modifications did not change the effect induced by the loperamide itself; however, chronic injection of BMS309403 at the dose of $1 \mathrm{mg} / \mathrm{kg}$ (i.p.) to mice fed with coconut oil $(\mathrm{COCO}+\mathrm{BMS})$ accelerated colonic transit over two times when compared to COCO group $(p<0.05)$ (4.667 \pm 1.08 and $1.833 \pm 0.600$, respectively).

\section{Chronic administration of BMS309403 to mice fed with either coconut oil or evening primrose oil significantly accelerated the onset of diarrhea}

We investigated the impact of chronic dietary supplementation with oils and the effect of the inhibition of FABP4 in the mouse model of diarrhea. The diarrhea was induced by the oral administration of castor oil, which causes accumulation of water and electrolytes in the intestine. In our study, both the supplementation with coconut oil (COCO group) and evening primrose oil (EPO group) delayed the onset of diarrhea, when compared to mice on a standard diet (STD group) (Fig. 4b).

Mice belonging to the COCO and EPO groups, which were additionally injected with BMS309403, had significantly reduced time to appearance of liquid feces when compared with respective dietary intervention without BMS309403 $(p<0.05 ; 81.80 \pm 6.34$ for COCO + BMS vs $147.5 \pm 18.54$ for $\mathrm{COCO}$, and $92.40 \pm 8.23$ for $\mathrm{EPO}+\mathrm{BMS}$ vs $158.8 \pm 14.96$ for EPO). The administration of BMS309403 to mice fed with STD diet did not affect time to occurrence of diarrhea.

\section{Supplementation with EPO increased VMR to CRD and BMS309403 administration reversed this effect}

To assess changes in visceral sensitivity between groups supplemented with oils and groups treated with BMS309403, we measured VMR to CRD. The pressure values ranging from 15 to $45 \mathrm{mmHg}$ did not affect the pain perception of animals. The maximum pressure used in the study $(60 \mathrm{mmHg})$ caused a significant increase in response to pain induced by balloon distention in EPO group, measured as the area under the curve ( $p<0.01$ vs. STD) (Figure S-1); the effect was reversed after the administration of BMS309403 $(p<0.01$ vs. EPO $+\mathrm{BMS})$. Figure $4 \mathrm{c}$ shows the effects of $60 \mathrm{mmHg}$ on VMR to CRD in all experimental groups.

\section{Dietary supplementation does not affect the expression of Fabp4 in the mouse colon}

To further characterize the influence of dietary supplementation and the effects of the pharmacological blockage of FABP4, we measured mRNA expression of Fabp4 in mouse colonic tissues. Fatty acid supplementation had no effect on the expression of Fabp4 in the colon (Fig. 5). Dietary supplementation with simultaneous administration of BMS309403 increased the mRNA expression of Fabp4 in 


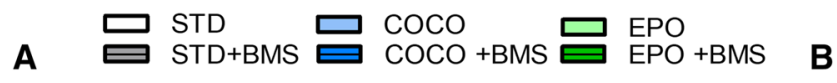
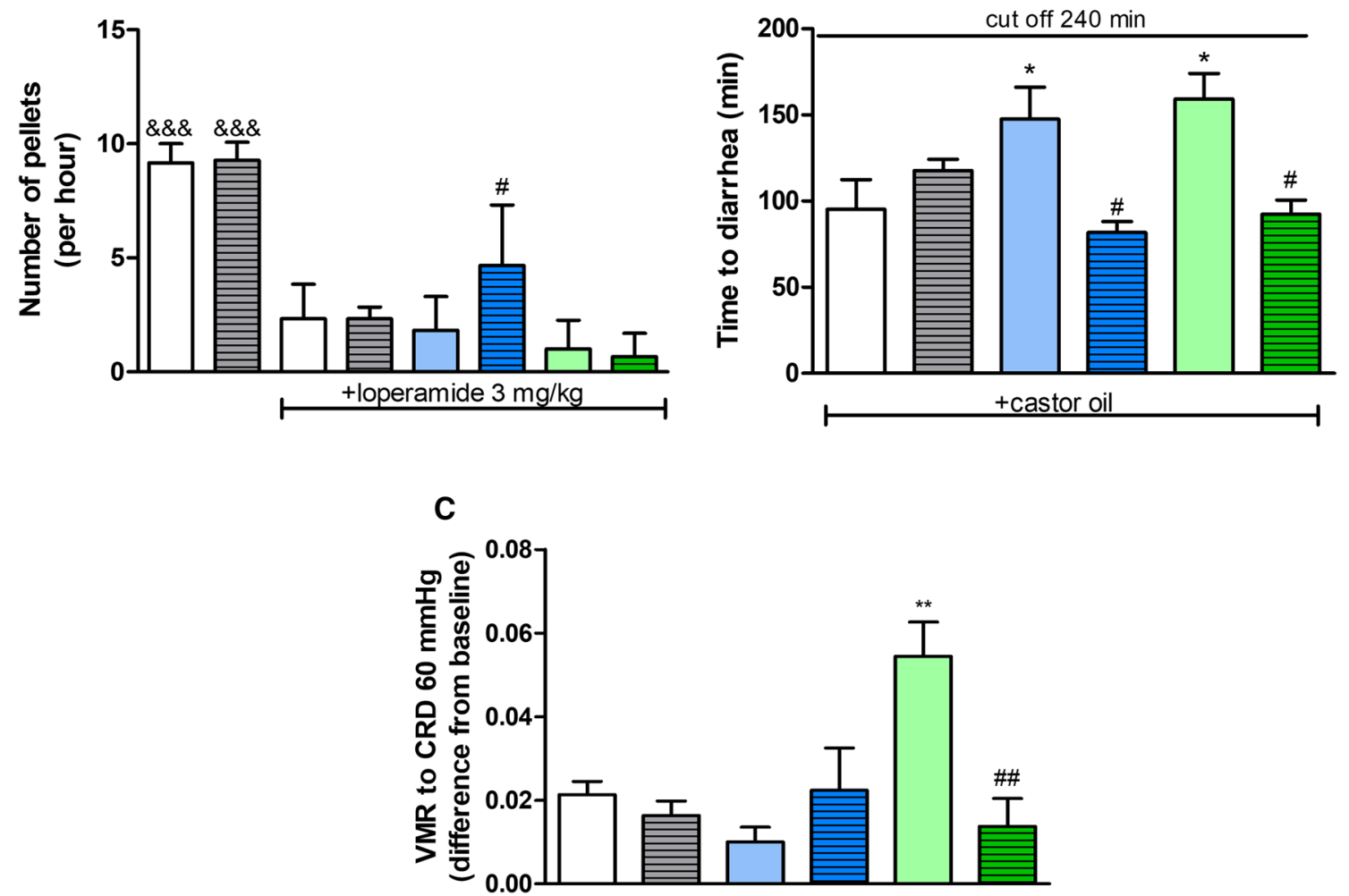

Fig. 4 The effect of different dietary interventions (STD, COCO and EPO) with or without the administration of BMS309403 $(1 \mathrm{mg} / \mathrm{kg}$, i.p.) on mouse GI motility and visceromotor response to colorectal distention (c). The GI motility was assessed in the mouse model of loperamide-induced hypomotility ( $3 \mathrm{mg} \mathrm{mg} / \mathrm{kg}$, i.p.) (a) and in castor oil-induced diarrhea $(200 \mu$ l, p.o.) (B). Data represent mean \pm SEM

$\mathrm{COCO}+\mathrm{BMS}$ and $\mathrm{EPO}+\mathrm{BMS}$ groups $(p<0.05$ vs. $\mathrm{COCO}$ and $p<0.01$ vs. EPO, respectively).

\section{Only diet with evening primrose oil suppressed the proliferation of preadipocytes}

Subsequently, we examined whether preadipocyte proliferation can be affected by diet or chronic treatment with BMS309403. As shown in the Fig. 6, the proliferation of cells isolated from the EPO-treated animals was significantly attenuated by $20 \%$ ( $p<0.001$, vs. STD group); COCO diet failed to produce any significant changes.

In contrast, the administration of FABP4 inhibitor BMS309403 significantly suppressed the proliferation of COCO + BMS-derived preadipocytes by $19 \%$ vs. STD + BMS, and by $23 \%$ vs. COCO. BMS309403 counteracted the anti-proliferative effect seen in EPO, leading to increased survivability of the EPO + BMS cells for about $12 \%(p<0.001$, vs. STD + BMS) and 32\% vs. EPO (Fig. 6). of $n=5-10$ mice per group. $* p<0.05$ and $* * p<0.01$ vs. STD; ${ }^{\& \&} p<0.001$ vs. STD + loperamide $\left(3 \mathrm{mg} / \mathrm{kg}\right.$, i.p.); ${ }^{\#} p<0.05$ and ${ }^{\# \#} p<0.01$ vs. respective dietary intervention without BMS309403 (one-way ANOVA followed by post hoc Newman-Keuls multiple comparison test)

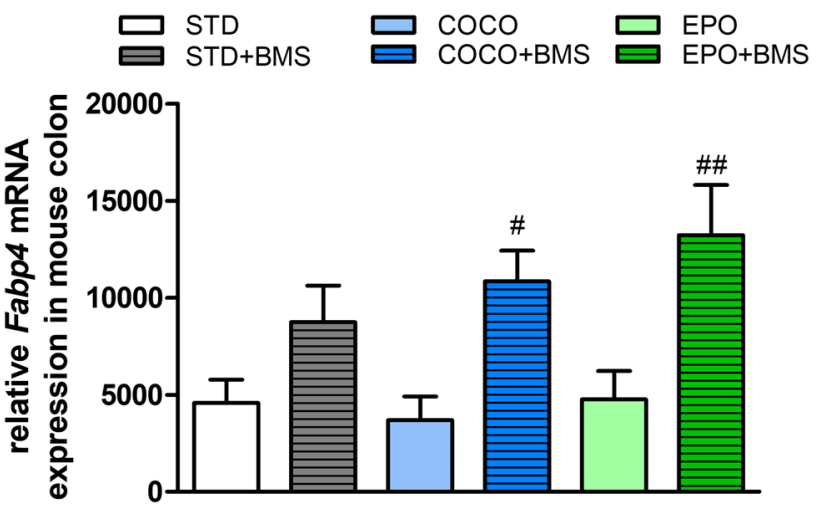

Fig. 5 The influence of different dietary interventions (STD, COCO and EPO) with or without the injection of BMS309403 $(1 \mathrm{mg} / \mathrm{kg}$, i.p.) on relative mRNA expression of FABP4 in mouse colonic tissue. Data represent mean \pm SEM of $n=5-6$ mice per group. ${ }^{\#} p<0.05$ and ${ }^{\# \#} p<0.01$ vs. respective dietary intervention without BMS309403 (one-way ANOVA followed by post hoc Newman-Keuls multiple comparison test) 


\section{The expression of Fabp4 in preadipocytes differed between $\mathrm{COCO}$ and EPO groups as well as between groups treated with BMS309403}

We measured the expression of Fabp 4 in preadipocytes isolated from mice fed with STD, COCO and EPO, and in mice which additionally received the treatment with the BMS309403 (Fig. 7).

Feeding with $\mathrm{COCO}$ had no effect on the Fabp4 expression in preadipocytes, whereas the supplementation with EPO significantly increased its level on the 1 st day following the onset of differentiation ( $p<0.01$ vs. cells from STD-fed mice) (Fig. 7a). On the 3rd day, the expression of Fabp4 decreased in both the COCO and EPO groups, reaching the statistical significance on day 6 following the induction of differentiation ( $p<0.001$ vs. STD-derived cells).

BMS309403 injected twice a week during the whole period of feeding changed the expression of Fabp 4 in preadipocytes isolated from the COCO and EPO groups (Fig. 7). On the 1st day of differentiation, a significant decrease in the relative mRNA expression of Fabp 4 was observed in preadipocytes derived from the $\mathrm{COCO}+\mathrm{BMS}$ group, when compared to the STD + BMS $(p<0.01)$ and COCO groups $(p<0.01$ and $p<0.05$, respectively). The mRNA expression of Fabp 4 cells isolated from the EPO+BMS group was significantly reduced only when compared to the EPO group $(p<0.01)$. On the 3rd day, the expression of Fabp4 in the $\mathrm{STD}+\mathrm{BMS}$ and $\mathrm{COCO}+\mathrm{BMS}$ groups decreased; however, these results were not significant. EPO + BMS did not show
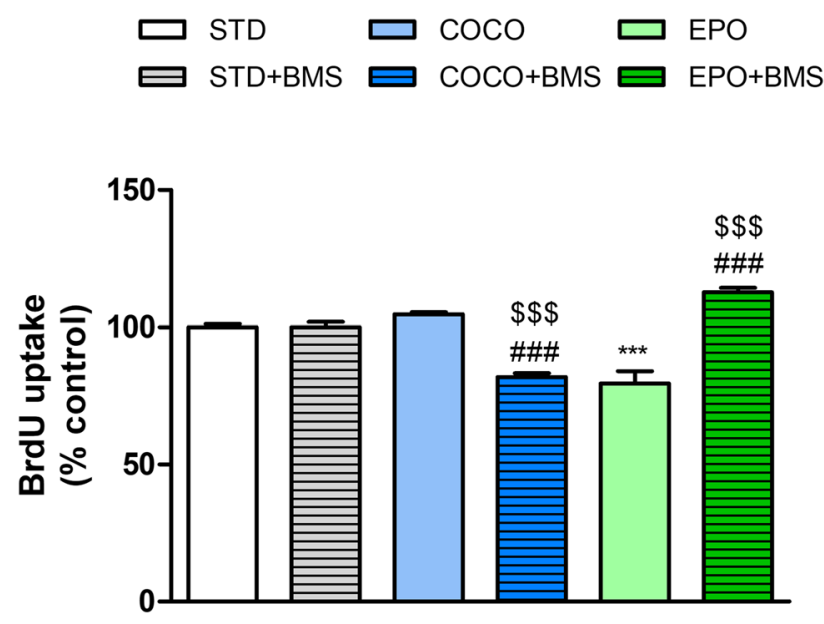

Fig. 6 The effects of 60 days of feeding with either a standard chow (STD), a STD supplemented with coconut oil (COCO) or STD supplemented with the evening primrose oil (EPO), without or with the administration of BMS309403, on preadipocyte proliferation. Data are expressed as mean \pm SEM for $n=24$. ***p $<0.001$, vs. cells isolated from the STD-fed mice; ${ }^{\$ \$} p<0.001$, vs. STD with BMS309403; \#\#\# $p<0.001$, vs. respective dietary intervention without BMS309403 (one-way ANOVA followed by post hoc NewmanKeuls multiple comparison test) any differences vs. STD + BMS or EPO groups. On the 6th day, the mRNA expression of Fabp4 in the STD+BMS and $\mathrm{COCO}+\mathrm{BMS}$ groups remained decreased and showed statistical difference vs. STD $(p<0.001)$ and COCO $(p<0.01)$ groups, respectively. No changes in the expression of Fabp 4 in the EPO+ BMS group were observed.

\section{Discussion}

There is a guideline consensus that diet and lifestyle advice should be the first-line approach in dietary treatment of IBS. Regular eating pattern, healthy eating habits (i.e., limiting the intake of potential dietary triggers, such as FODMAPs, spicy foods, caffeine or alcohol), and regular physical activity are typical lifestyle modifications recommended by specialists [35-37]. A vast proportion of patients with IBS relate their symptoms to foods rich in fat $[38,39]$. Despite the limited evidence on the association between the intake of fats, and in particular of FAs, and the occurrence of IBS symptoms, elimination or the avoidance of food rich in fat is one of the approaches considered to improve patient's wellbeing and their quality of life $[40,41]$. Since laboratorybased studies are scarce and the clinical studies limited, we aimed at evaluating changes in the GI motility and visceral pain of animals exposed to different dietary interventions, and determine whether the observed effects can be regulated through the inhibition of the FABP4-dependent pathway.

Our results demonstrated that mice fed with diet rich in MCFAs (COCO group) showed typical body weight gain throughout the experiment. This corroborated previous outcome that weight gain in vivo depends on the FA composition of the diet, and that diet rich in MCFAs is non-obesogenic [42-44]. This may come from the fact that MCFAs are readily absorbed from the intestines directly into the portal vein, transported to the liver where they undergo beta-oxidation via carnitine-independent mechanism, and thus increase diet-induced thermogenesis. Our outcomes are in line with other observations [45-47].

In contrast, we noticed a substantial drop in the body weight in the EPO group, i.e., animals supplemented with LCFAs, with no effect on food intake. These effects of EPO are mainly attributed to the content of gamma-linolenic and linoleic acids (LA), which are precursors of omega-3 FAs, such as docosahexaenoic and eicosapentaenoic acids. Conjugated LA (CLA), a product of symbiotic fermentative bacteria which transform LA into its conjugated form, is considered as a bioactive compound, which exhibits antiobesity effects by influencing lipid metabolism, i.e., reduces fat accumulation in adipose tissue and increases hepatic lipogenesis. Accordingly, CLA reduced body fat accumulation by increasing energy expenditure and endurance capacity within one week of feeding, and sustained it for more than 

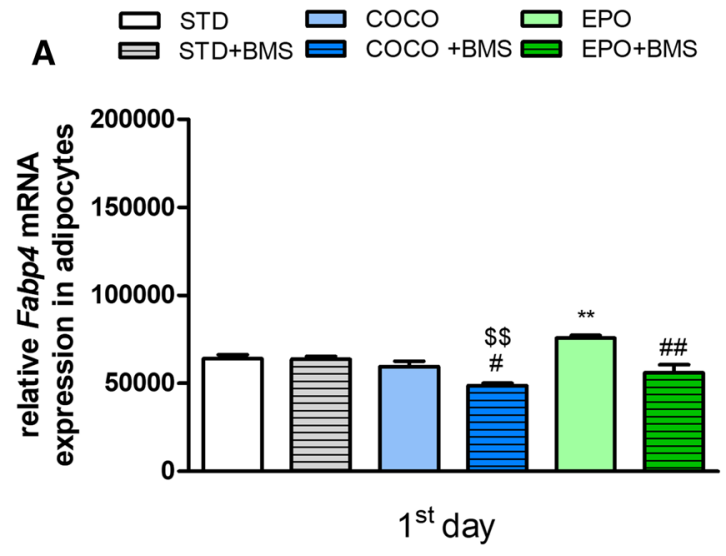

B

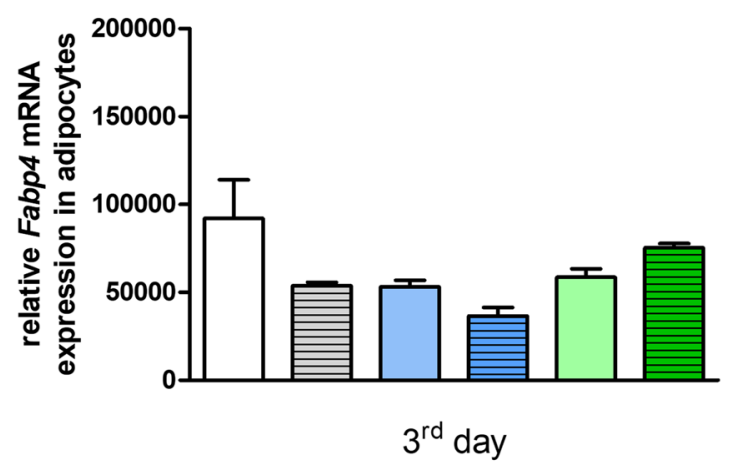

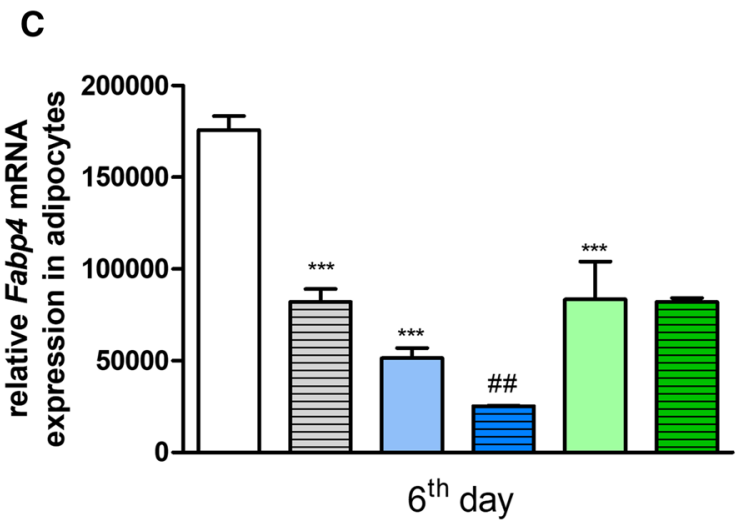

Fig. 7 The relative mRNA expression of Fabp4 in preadipocytes isolated from animals fed with either standard chow (STD), standard chow supplemented with coconut oil (COCO) or evening primrose oil (EPO), without and with the administration of BMS309403 (1 mg/ $\mathrm{kg}$, i.p.). The cells were harvested on the 1st (a), 3rd (b) and 6th (c) days following the induction of differentiation. Data are expressed

6 weeks without affecting the food intake [48]. Since CLAs are a family of isomers of LAs that could be found in EPO, it is also possible that the reduction in body weight seen in our study could be related to more intense locomotor activity of animals, which resulted in increased lipid metabolism. Albeit, as we did not evaluate energy expenditure or the exercise performance of animals throughout the study, we can only speculate about their possible contribution to the observed effect. Likewise, other studies also reported a substantial increase in the voluntary movement between 4 and 20 weeks of feeding with CLA, and decrease or no change in the body weight [49-52].

Concurrently, throughout the period of feeding, the cumulative food intake in both $\mathrm{COCO}$ and EPO groups was similar to STD, which provides additional evidence that supplementation with MCFAs, derived from coconut oil, or LCFAs, found in evening primrose oil, do not influence the appetite of animals. These findings are in accordance with other studies [52-54]. as mean \pm SEM $* * p<0.01, * * * p<0.001$, vs. cells isolated from the STD-fed mice; ${ }^{\$} p<0.01$, vs. STD with BMS309403; ${ }^{\#} p<0.05$, ${ }^{\# \#} p<0.01$, vs. respective dietary intervention without BMS309403 (one-way ANOVA followed by post hoc Newman-Keuls multiple comparison test)

FABP4 was first identified in mature adipocytes and macrophages but recently its high expression was also detected in intestinal epithelial cells and in colonic mouse samples $[21,22]$. Although FABP4 exhibits higher affinity towards saturated FAs, it also binds to unsaturated FAs and retinoic acid. The protein not only facilitates FA transport and metabolism, but also acts as signaling molecule that distributes or sequesters FAs to control signaling pathways and gene expression. Various studies showed that FABP4-deficient mice gained more weight upon induction of dietary obesity $[55,56]$. Moreover, given the fact that FABP4 exerts higher affinity towards LCFAs than MCFAs, the increase in body weight was much more visible in the EPO + BMS group than in the $\mathrm{COCO}+\mathrm{BMS}$ group at the end of the study. Besides the differences observed between $\mathrm{COCO}+\mathrm{BMS}$ or $\mathrm{EPO}+\mathrm{BMS}$ and respective dietary intervention without the injection of BMS309403, a remarkable change in cumulative food intake has also been noted between the STD+BMS and $\mathrm{EP}+\mathrm{BMS}$ groups (between 30 and 60 days of feeding). It 
additionally indicates that the amount of food consumed by animals depended not only on the presence of BMS309403, but also on the content of FAs in a diet. The more PUFAs in a diet, the higher the amount of food consumed by animals.

Dietary FA supplementation influences GI motility in vivo; the effect it generates is dependent on the chain length and the type of FAs consumed. So far, both MCFAs and LCFAs have been evaluated mainly in regards of their effects on upper gut motility; few studies have focused on their effects on the lower GI motility. We hypothesized that dietary supplementation with coconut oil, which results in higher content of lauric acid (12 carbon atoms), can increase the bowel motility and that the effect would be greater than after the supplementation with evening primrose oil, in which the major component is the linoleic acid (18 carbon atoms). As expected, animals treated with MCFAs (COCO group) had significantly increased GI motility, which was evaluated based on the number of pellets excreted within a specified period of time. In contrast, animals supplemented with LCFAs (EPO group) did not show any differences when compared to STD group. Moreover, none of the diets affected colonic motility, which may suggest that the effect of FAs on motility depends on the location of FAs in the GI tract, i.e., the same type of FAs can exert different, even opposite effects whether it concerns the upper part of the digestive tract or the large intestine. The radiographic studies in rats showed that the supplementation with 3.5\% EPO resulted in a slightly faster propel of the barium from the stomach to the colon when compared to animals supplemented with $3.5 \%$ soybean oil [57]. Although the matter content reached the colon faster, the EPO diet induced the strongest (but still not statistically significant) inhibitory effect on propulsive colonic motility. In humans, indirect comparison of results from different studies showed that LCFAs with $\geq 12$ carbon atoms slow gastric emptying and affect antropyloroduodenal motility [58] more than MCFAs with $\leq 12$ carbon atoms [59]. The intragastric administration of lauric acid, a saturated FA, to humans caused relaxation of the fundus and reduced the amplitude of antral contractions. The effect was more intense than after the infusion of capric acid (10 carbon atoms), which markedly stimulated duodenal pressure waves and had no effects on antral pressure waves. Other studies evaluated the effects of intraduodenal infusion of FAs to humans. The studies revealed that intraduodenal infusion of lauric acid stimulated pyloric motility and increased the number and amplitude of phasic and basal pyloric pressure waves more than the infusion of oleic acid (a monounsaturated FA with 18 carbon atoms). As concluded by the authors, the greater the load of lauric acid, the greater the stimulation of basal pyloric pressure and decrease in antral and duodenal pressure [59]. Taking into consideration that the animals in our study consumed similar amount of chow, and that the percentage of FAs in each diet was equal (7\%), the observed changes in GI motility could only be attributed to the mechanism of action of a particular type of FA included in a diet. Nevertheless, it would be of particular importance for the future studies to 1) measure the amount of FAs that reach the intestine; 2) evaluate whether the increase in GI motility occurred as a result of greater (or certain) area of the small intestine that contacted the FA and therefore modulates their absorptive capacity; and 3) highlight the correlation between the chain length of FA and their absorption in the intestines.

In our study, the type of FAs in a diet neither significantly affected the colonic motility nor the mRNA expression of Fabp4 in the colon. However, the administration of BMS309403 remarkably delayed the colonic motility of mice treated with STD + BMS and $\mathrm{COCO}+\mathrm{BMS}$, when compared to their respective dietary intervention without BMS309403, and slightly increased the motility in the EPO + BMS group vs. EPO. Moreover, the mRNA expression of Fabp4 in BMS309403-treated animals varied between groups. The changes were dependent on the type of FAs present in the diet. Our results suggest that the longer the chain length of FAs, the higher the mRNA expression of Fabp4 in the colon and the greater increase in colonic motility of animals treated with BMS309403. Since LCFAs are considered as more potent ligands for FABP4 than MCFAs, the inhibition of this protein may result in higher accumulation of LCFAs in colonic lumen.

Constipation and diarrhea are major ailments of the GI tract, which are common amongst patients with IBS. To characterize the effects of coconut oil and evening primrose oil supplementation, we employed experimental mouse models of pharmacologically induced constipation and used the laxative properties of castor oil to induce diarrhea. The treatment with loperamide caused a significant reduction of the intestinal transit, when compared to non-constipated animals, and this effect was maintained regardless of the applied interventions. Loperamide exerts its activity through the $\mu$ opioid receptors, which are expressed in the intestines. Since none of the interventions increased the effect of loperamide, it can be presumed that the expression of these receptors was not altered. In our previous study, we demonstrated that acute injection of BMS309043 had beneficial effects in alleviating constipation-like symptoms by accelerating colonic transit [22]. In the present study, the treatment with BMS309403 improved colonic propulsion and promoted forward movement of the contents of the small intestine toward the colon, thereby relieving constipation but only in the group supplemented with MCFA (COCO + BMS). Whether these effects occurred due to changes in the expression of $\mu$ opioid receptors still needs to be verified.

The active principle of castor oil is known to change the electrolyte permeability of the intestinal membrane and through elevated prostaglandin biosynthesis and release it 
causes diarrhea-similar to pathophysiologic conditions that cause diarrhea in humans [60]. In a castor oil-induced diarrhea, the supplementation with MCFAs (COCO group) as well as with LCFAs (EP group) had preventive effects against diarrhea by prolonging the time to appearance of liquid faeces. MCFAs and LCFAs could induce such changes by delaying transit in either upper or lower GI tract, or by increasing absorption of water and electrolytes through the intestinal wall, which consequently slowed down the secretion of fluid in the GI tract. Chronic treatment with BMS309403 significantly accelerated GI transit, when compared to dietary intervention without BMS309403 administration. It indicates that BMS309403 antagonizes the effect of diets in the model of castor oil-induced diarrhea by inhibiting the transport of FAs through the intestinal wall in FABP4-dependent manner.

In patients with FGIDs, modulatory mechanisms that regulate the sensory-reflex pathways are abnormal, and depending on the region affected, can lead to symptom generation or exacerbation. Several studies showed that intraduodenal infusion of fat (Intralipid solution) can affect the responses of the gut to different stimuli leading to gut hypersensitivity and disturbed reflexes [61-63]. However, it is worth mentioning that the major ingredient of the Intralipid solution is soybean oil, which in turn is a source of PUFAs, particularly FA composed of 18 carbon atoms. In our study, EPO increased pain perception at the highest pressure, which indicates that animals were more sensitive to CRD than animals from STD or COCO groups. A study incorporating a 28-day-long dietary intervention showed that rats fed with $3.5 \%$ of coconut oil or evening primrose oil inhibited colonic sensitivity to mechanical stimulation at the lower pressure values ( 15 and $30 \mathrm{mmHg}$ ), but had no influence on abdominal muscle motor function (measured as the duration of contractions) [57]. At higher pressure values (60 and $75 \mathrm{mmHg}$ ), rats exhibited similar sensitivity to mechanical stimulation, including the number, duration and the $\%$ of time with abdominal contraction to a group fed with $3.5 \%$ of soybean oil [57]. The effects of evening primrose oil on pain perception varied between studies. The differences may stem from the time of feeding, the concentration of FAs in the diet and the type of stimulation used to elicit contractions, i.e., phasic stimulation in the previous study on rats, and tonic stimulation in the current study.

The administration of BMS309403 reversed the effects caused by EPO. If the observed changes in visceral sensation were dependent on the type of FAs in a diet, it is possible that the effects were mediated through FABP4 activation since it has higher affinity towards the LCFAs.

In our earlier studies, we examined the presence and distribution of FABP4 and its possible co-expression with neuronal and endothelial markers in the colon, and verified whether BMS309403 can elicit functional changes in neuronal input to the circular smooth muscle in vivo [22]. We demonstrated that FABP4 was not co-localized with neuronal marker-beta tubulin, and did not induce electrophysiological changes in membrane potential of isolated colonic muscles. Likewise, in the present study, BMS309403 did not alter the sensation in response to CRD. Thus, taking all the findings together, we can rule out the hypothesis of the possible interaction of FABP4 and neuronal afferent nerves in the mouse GI tract and exclude the involvement of BMS30403 in promoting visceral sensitivity or generating changes in colonic neurotransmission.

Supplementation with FAs can effectively regulate the body fat by increasing the volume of adipocytes; therefore, in our studies, we also focused on analysis of primary fat cells, and examined the effects of diets and BMS309403 on preadipocyte proliferation and differentiation. We showed that proliferation of preadipocytes was not affected by the supplementation with COCO; however, it was significantly hampered by the treatment with EPO. The observed effect of EPO on preadipocyte proliferation is in accordance with other studies, which documented the anti-proliferative effects of LCFAs (particularly conjugated LA) on preadipocytes, which impeded the growth of lipid depots [64]. The treatment with BMS309403 substantially decreased the proliferation of $\mathrm{COCO}+\mathrm{BMS}$-derived cells and increased the proliferation in the $\mathrm{EPO}+\mathrm{BMS}$ group.

FABP4 is highly expressed in mature adipocytes. Studies showed that expression of Fabp4 is regulated mostly by saturated and monounsaturated FAs. However, more recently, it has been proven that LCFAs inhibit adipocyte differentiation and lipid accumulation in vitro, contributing to a decrease in the expression and consecutive long-term secretion, but not short-term secretion, of Fabp4 [65, 66]. In the present study, COCO diet did not influence adipogenesis at the 1st and 3rd days since initiation of differentiation but it significantly reduced adipogenesis at the last day of differentiation, by decreasing the expression of Fabp4. In vitro studies on 3T3-L1 primary cells demonstrated that treatment with coconut oil, CLA or with lauric acid reduced fat accumulation in adipocyte during their differentiation, and decreased the expression of adipogenic nuclear factors [67]. Moreover, they failed to increase the level of Fabp 4 mRNA after induction of differentiation. In contrast, cells from the EPO group displayed the highest expression of Fabp 4 at the 1st day following the induction of differentiation and significantly lowered its expression at 6th day, when compared to STD group.

Although dietary supplementation with MCFAs and LCFAs significantly decreased adipogenesis at 6th day (since initiation of differentiation), our results suggest that adipogenesis process depends on the uptake of circulating FAs. The differentiation of preadipocytes at day 6 was higher in EPO group than COCO group indicating that 
supplementation with LCFA contributed to higher uptake of FAs, and thus higher lipid accumulation. This result can be related to high concentration of LA in EPO group. Generally, LA is thought to depress preadipocytes proliferation and de novo lipogenesis, and reduce fat accumulation in growing animals [68]. LCFAs activate a metabolic switch and contribute to lipid catabolism and suppression of lipogenesis, which also explains decrease in body weight of animals from the EPO group. However, it has to be emphasized that depending on the content of LA in a diet, LCFAs can exert different effects on adipogenesis. Even though STD diet contained LAs, the concentration of this FA was lower than in EPO diet, and was associated with increased differentiation of preadipocytes at 6th day. In line, treatment with stearidonic acid suppressed adipocyte differentiation and lipid accumulation by reducing the expression of transcription factors, including FABP4 [69]. Therefore, qualitative but not quantitative change in LCFAs can reduce Fabp4 expression [65], and so, various sources of LCFAs can exert different effects on its expression. Moreover, as suggested by Prostak et al. [66], the influence of LCFAs can be age related, i.e., young cells seem to be more sensitive to LCFAs than mature and old ones.

BMS309403 appears to inhibit differentiation of preadipocyte at an early stage of differentiation in both $\mathrm{COCO}+\mathrm{BMS}$ and EPO+BMS groups. However, it exerted the highest inhibitory potency towards $\mathrm{COCO}$-derived mature adipocytes, and not towards differentiated mature EPO cells. BMS309403 can differently influence adipogenesis and the Fabp4 gene expression, which may be related to the chain length or degree of unsaturation of FAs.

The present study is subject to some limitations. First, we did not incorporate animal models of IBS induced by alternating exposure to stress, e.g., maternal separation or the water avoidance stress, which in light of our observations could provide clearer results regarding the role of dietary interventions on the GI motility. Second, the consistency of fecal pellets and the FA content in the fecal matter have not been evaluated. Third, we did not verify whether the changes in the mRNA expression of FABP4 are accompanied by changes in the protein expression (e.g., by performing the Western Blot or Immunohistochemistry).

\section{Conclusions}

The results obtained herein are of significance for several reasons. First, our data imply that FA supplementation with MCFAs or LCFAs regulates GI motility and that the effect might be dependent on the presence of FABP4 in the intestines. Secondly, FAs affect GI transit differently in physiological conditions and in mouse models mimicking IBS symptoms, i.e., models of constipation and diarrhea.
Moreover, administration of FABP4 inhibitor, BMS309403, triggers a shift in the effects of MCFAs on GI motility but it does not significantly change the pain perception in vivo. The control of the mRNA expression of FABP4 appears to play a dominant role in overall GI motility (in these settings). It remains to be established whether BMS309403 impacts the function of FABP4 that is present in the intestines, or inhibits FABP4 in adipocytes where it affects the adipocyte-derived signals that modulate GI motility. Finally, our findings highlight the importance of dietary FAs in maintaining body homeostasis and control the course of the disease, and suggest possible therapeutic use of a synthetic FABP4 inhibitor in GI disorders, particularly IBS.

Acknowledgements Supported by the Medical University of Lodz (\#502-03/1-156-04/502-14-343-17, \#502-03/1-156-04/502-14-34318 to PM and \#503/1-156-04/503-11-001 to JF) and National Science Center (\#UMO-2016/21/N/NZ5/01932 to PM).

Author contributions PM, JF and MS provided the overall concept and designed the research study; PM, ASz and TW conducted experiments; PM analyzed the data and wrote the manuscript. All authors regularly discussed the experiments and data, suggested adjustments of the experimental protocols, read and approved the final version of the manuscript.

\section{Compliance with ethical standards}

Conflict of interest The authors have no competing interests.

Open Access This article is distributed under the terms of the Creative Commons Attribution 4.0 International License (http://creativeco mmons.org/licenses/by/4.0/), which permits unrestricted use, distribution, and reproduction in any medium, provided you give appropriate credit to the original author(s) and the source, provide a link to the Creative Commons license, and indicate if changes were made.

\section{References}

1. Oshima T, Miwa H (2015) Epidemiology of Functional Gastrointestinal Disorders in Japan and in the World. J Neurogastroenterol Motil 21:320-329. https://doi.org/10.5056/jnm14165

2. Chey WD, Kurlander J, Eswaran S (2015) Irritable bowel syndrome: a clinical review. JAMA 313:949-958. https://doi. org/10.1001/jama.2015.0954

3. Saito YA, Schoenfeld P, Locke GR 3rd (2002) The epidemiology of irritable bowel syndrome in North America: a systematic review. Am J Gastroenterol 97:1910-1915. https://doi.org/10.11 11/j.1572-0241.2002.05913.x

4. Lovell RM, Ford AC (2012) Global prevalence of and risk factors for irritable Bowel syndrome: a meta-analysis. Clin Gastroenterol Hepatol 10:712-721. https://doi.org/10.1016/j.cgh.2012.02.029

5. Palsson OS, Whitehead WE, van Tilburg MAL et al (2016) Development and validation of the Rome IV Diagnostic Questionnaire for adults. Gastroenterology 150:1481-1491. https://doi. org/10.1053/j.gastro.2016.02.014

6. Böhn L, Störsrud S, Törnblom H et al (2013) Self-reported food-related gastrointestinal symptoms in IBS are common and 
associated with more severe symptoms and reduced quality of life. Am J Gastroenterol 108:634-641. https://doi.org/10.1038/ ajg.2013.105

7. El-Salhy M, Gilja OH, Gundersen D et al (2014) Interaction between ingested nutrients and gut endocrine cells in patients with irritable bowel syndrome (review). Int J Mol Med 34:363-371. https://doi.org/10.3892/ijmm.2014.1811

8. El-Salhy M, Ostgaard H, Gundersen D et al (2012) The role of diet in the pathogenesis and management of irritable bowel syndrome (review). Int J Mol Med 29:723-731. https://doi.org/10.3892/ ijmm.2012.926

9. De Giorgio R, Volta U, Gibson PR, Gibson P (2016) Sensitivity to wheat, gluten and FODMAPs in IBS: facts or fiction? Gut 65:169-178. https://doi.org/10.1136/gutjnl-2015-309757

10. Gibson PR, Barrett JS, Muir JG (2013) Functional bowel symptoms and diet. Intern Med J 43:1067-1074. https://doi. org/10.1111/imj.12266

11. Islam KBMS, Fukiya $S$, Hagio M et al (2011) Bile acid is a host factor that regulates the composition of the cecal microbiota in rats. Gastroenterology 141:1773-1781. https://doi.org/10.1053/j. gastro.2011.07.046

12. Caldarella MP, Milano A, Laterza F et al (2005) Visceral sensitivity and symptoms in patients with constipation- or diarrheapredominant Irritable Bowel Syndrome (IBS): effect of a low-fat intraduodenal infusion. Am J Gastroenterol 100:383-389. https ://doi.org/10.1111/j.1572-0241.2005.40100.x

13. Simrén M, Abrahamsson H, Björnsson ES (2007) Lipid-induced colonic hypersensitivity in the irritable bowel syndrome: the role of bowel habit, sex, and psychologic factors. Clin Gastroenterol Hepatol 5:201-208. https://doi.org/10.1016/j.cgh.2006.09.032

14. Torres MJ, Sabate J-M, Bouchoucha M et al (2018) Food consumption and dietary intakes in 36,448 adults and their association with irritable bowel syndrome: Nutrinet-Santé study. Ther Adv Gastroenterol 11:1756283X1774662. https://doi. org/10.1177/1756283X17746625

15. Park JH, Kwon OD, Ahn SH et al (2013) Fatty diets retarded the propulsive function of and attenuated motility in the gastrointestinal tract of rats. Nutr Res 33:228-234. https://doi.org/10.1016/j. nutres.2012.12.008

16. Clarke G, Fitzgerald P, Hennessy A et al (2010) Marked elevations in pro-inflammatory polyunsaturated fatty acid metabolites in females with irritable bowel syndrome. J Lipid Res 51:11861192. https://doi.org/10.1194/jlr.P000695

17. Solakivi T, Kaukinen K, Kunnas T et al (2011) Scandinavian Journal of Gastroenterology Serum fatty acid profile in subjects with irritable bowel syndrome serum fatty acid profile in subjects with irritable bowel syndrome. Scand J Gastroenterol 463:299-303. https://doi.org/10.3109/00365521.2010.533380

18. Russo F, Chimienti G, Clemente $\mathrm{C}$ et al (2013) Adipokine profile in celiac patients: differences in comparison with patients suffering from diarrhea-predominant IBS and healthy subjects. Scand J Gastroenterol 48:1377-1385. https://doi.org/10.3109/00365 521.2013.845907

19. Liu D-R, Xu X-J, Yao S-K (2018) Increased intestinal mucosal leptin levels in patients with diarrhea-predominant irritable bowel syndrome. World J Gastroenterol 24:46-57. https://doi. org/10.3748/wjg.v24.i1.46

20. Semnani S, Roshandel G, Keshtkar A et al (2009) Serum leptin levels and irritable Bowel syndrome. J Clin Gastroenterol 43:826830. https://doi.org/10.1097/MCG.0b013e3181986900

21. Su X, Yan H, Huang Y et al (2015) Expression of FABP4, adipsin and adiponectin in Paneth cells is modulated by gut Lactobacillus. Sci Rep 21(5):18588. https://doi.org/10.1038/srep18588

22. Mosińska P, Jacenik D, Sałaga M et al (2018) FABP4 blocker attenuates colonic hypomotility and modulates white adipose tissue-derived hormone levels in mouse models mimicking constipation-predominant IBS. Neurogastroenterol Motil 30:e13272. https://doi.org/10.1111/nmo.13272

23. Reeves PG, Nielsen FH, Fahey GC (1993) AIN-93 purified diets for laboratory rodents: final report of the American Institute of Nutrition Ad Hoc Writing Committee on the Reformulation of the AIN-76A Rodent Diet. J Nutr 123:1939-1951. https://doi. org/10.1093/jn/123.11.1939

24. Fichna J, Sałaga M, Stuart J et al (2014) Selective inhibition of FAAH produces antidiarrheal and antinociceptive effect mediated by endocannabinoids and cannabinoid-like fatty acid amides. Neurogastroenterol Motil 26:470-481. https://doi.org/10.1111/ nmo. 12272

25. Fichna J, Schicho R, Andrews CN et al (2009) Salvinorin A inhibits colonic transit and neurogenic ion transport in mice by activating $\kappa$-opioid and cannabinoid receptors. Neurogastroenterol Motil 21:1326-e128. https://doi.org/10.1111/j.1365-2982.2009.01369.x

26. Sałaga M, Polepally PR, Sobczak M et al (2014) Novel orally available salvinorin A analog PR-38 inhibits gastrointestinal motility and reduces abdominal pain in mouse models mimicking irritable bowel syndromes. J Pharmacol Exp Ther J Pharmacol Exp Ther 350:69-78. https://doi.org/10.1124/jpet.114.214239

27. Fichna J, Sobczak M, Mokrowiecka A et al (2014) Activation of the endogenous nociceptin system by selective nociceptin receptor agonist SCH 221510 produces antitransit and antinociceptive effect: a novel strategy for treatment of diarrhea-predominant IBS. Neurogastroenterol Motil 26:1539-1550. https://doi.org/10.1111/ nmo. 12390

28. Chen C, Lu M, Pan Q et al (2015) Berberine improves intestinal motility and visceral pain in the mouse models mimicking diarrhea-predominant irritable Bowel syndrome (IBS-D) symptoms in an opioid-receptor dependent manner. PLoS One 10:e0145556. https://doi.org/10.1371/journal.pone.0145556

29. Skrzypski M, Pruszyńska-Oszmałek E, Ruciński M et al (2012) Neuropeptide $\mathrm{B}$ and $\mathrm{W}$ regulate leptin and resistin secretion, and stimulate lipolysis in isolated rat adipocytes. Regul Pept 176:5156. https://doi.org/10.1016/j.regpep.2012.03.004

30. Chatterjee TK, Idelman G, Blanco V et al (2011) Histone deacetylase 9 is a negative regulator of adipogenic differentiation. J Biol Chem 286:27836-27847. https://doi.org/10.1074/jbc.M111.26296 4

31. Wojciechowicz T, Skrzypski M, Koodziejski PA et al (2015) Obestatin stimulates differentiation and regulates lipolysis and leptin secretion in rat preadipocytes. Mol Med Rep 12:8169-8175. https://doi.org/10.3892/mmr.2015.4470

32. Skrzypski M, Kaczmarek P, Le TT et al (2012) Effects of orexin A on proliferation, survival, apoptosis and differentiation of 3T3-L1 preadipocytes into mature adipocytes. FEBS Lett 586:4157-4164. https://doi.org/10.1016/j.febslet.2012.10.013

33. Włodarczyk M, Sobolewska-Włodarczyk A, Cygankiewicz AI et al (2017) G protein-coupled receptor 30 (GPR30) expression pattern in inflammatory Bowel disease patients suggests its key role in the inflammatory process. A preliminary study. J Gastrointestin Liver Dis 26:29-35. https://doi.org/10.15403/ jgld.2014.1121.261.gpr

34. Curtis MJ, Bond RA, Spina D et al (2015) Experimental design and analysis and their reporting: new guidance for publication in BJP. Br J Pharmacol 172:3461-3471. https://doi.org/10.1111/ bph. 12856

35. Khayyatzadeh SS, Kazemi-Bajestani SMR, Mirmousavi SJ et al (2018) Dietary behaviors in relation to prevalence of irritable bowel syndrome in adolescent girls. J Gastroenterol Hepatol 33:404-410. https://doi.org/10.1111/jgh.13908

36. El-Salhy M, Gundersen D (2015) Diet in irritable bowel syndrome. Nutr J 14:36. https://doi.org/10.1186/s12937-015-0022-3

37. Reed-Knight B, Squires M, Chitkara DK, Van Tilburg MA (2016) Adolescents with irritable bowel syndrome (IBS) report increased 
eating associated symptoms, changes in dietary composition, and altered eating behaviors: a pilot comparison study to healthy adolescents. Neurogastroenterol Motil 28(12):1915-1920. https://doi. org/10.1111/nmo.12894

38. Williams EA, Nai X, Corfe BM (2011) Dietary intakes in people with irritable bowel syndrome. BMC Gastroenterol 3(11):9. https ://doi.org/10.1186/1471-230X-11-9

39. Saito YA, Locke GR, Weaver AL et al (2005) Diet and functional gastrointestinal disorders: a population-based case-control study. Am J Gastroenterol 100:2743-2748. https://doi.org/10.4321/ S0004-05922011000300032

40. Simrén M, Månsson A, Langkilde AM et al (2001) Food-related gastrointestinal symptoms in the irritable bowel syndrome. Digestion 63:108-15. https://doi.org/10.1159/000051878

41. Hayes P, Corish C, O’Mahony E, Quigley EMM (2014) A dietary survey of patients with irritable bowel syndrome. J Hum Nutr Diet 27:36-47. https://doi.org/10.1111/jhn.12114

42. Turner N, Hariharan K, TidAng J et al (2009) Enhancement of muscle mitochondrial oxidative capacity and alterations in insulin action are lipid species dependent: potent tissue-specific effects of medium-chain fatty acids. Diabetes 58:2547-2554. https://doi. org/10.2337/db09-0784

43. Takeuchi H, Sekine S, Kojima K, Aoyama T (2008) The application of medium-chain fatty acids: edible oil with a suppressing effect on body fat accumulation. Asia Pac J Clin Nutr 17(Suppl 1):320-323

44. Žáček P, Bukowski M, Mehus A et al (2019) Dietary saturated fatty acid type impacts obesity-induced metabolic dysfunction and plasma lipidomic signatures in mice. J Nutr Biochem 64:32-44. https://doi.org/10.1016/j.jnutbio.2018.10.005

45. Nurul-Iman BS, Kamisah Y, Jaarin K, Qodriyah HMS (2013) Virgin coconut oil prevents blood pressure elevation and improves endothelial functions in rats fed with repeatedly heated palm oil. Evid Based Complement Altern Med 2013:629329. https://doi. org/10.1155/2013/629329

46. Lee Y-Y, Tang T-K, Phuah E-T et al (2018) Structural difference of palm based medium- and long-chain triacylglycerol (MLCT) further reduces body fat accumulation in DIO C57BL/6J mice when consumed in low fat diet for a mid-term period. Food Res Int 103:200-207. https://doi.org/10.1016/j.foodres.2017.10.022

47. Zhou S, Wang Y, Jiang Y et al (2017) Dietary intake of structured lipids with different contents of medium-chain fatty acids on obesity prevention in C57BL/6J mice. J Food Sci 82:1968-1977. https ://doi.org/10.1111/1750-3841.13789

48. DeLany JP, West DB (2000) Changes in body composition with conjugated linoleic acid. J Am Coll Nutr 19:487S-493S

49. West DB, Blohm FY, Truett AA, DeLany JP (2000) Conjugated linoleic acid persistently increases total energy expenditure in $\mathrm{AKR} / \mathrm{J}$ mice without increasing uncoupling protein gene expression. J Nutr 130:2471-2477. https://doi.org/10.1093/ jn/130.10.2471

50. Park Y, Park Y (2012) Conjugated fatty acids increase energy expenditure in part by increasing voluntary movement in mice. Food Chem 133:400-409. https://doi.org/10.1016/j.foodc hem.2012.01.051

51. Lee S-R, Khamoui AV, Jo E et al (2017) Effect of conjugated linoleic acids and omega-3 fatty acids with or without resistance training on muscle mass in high-fat diet-fed middle-aged mice. Exp Physiol 102:1500-1512. https://doi.org/10.1113/EP086317

52. Takada R, Saitoh M, Mori T (1994) Dietary $\gamma$-linolenic acidenriched oil reduces body fat content and induces liver enzyme activities relating to fatty acid $\beta$-oxidation in rats. J Nutr 124:469474. https://doi.org/10.1093/jn/124.4.469

53. Javadi M, Everts H, Hovenier R et al (2018) The effect of six different $\mathrm{C} 18$ fatty acids on body fat and energy metabolism in mice. Br J Nutr 92(3):391-399. https://doi.org/10.1079/BJN20041217
54. Nazari M, Saberi A, Karandish M, Jalali M (2018) Adipose tissue miRNA level variation through conjugated linoleic acid supplementation in diet-induced obese rats. Adv Clin Exp Med 27:1477-1482. https://doi.org/10.17219/acem/93728

55. Uysal KT, Scheja L, Wiesbrock SM et al (2000) Improved glucose and lipid metabolism in genetically obese mice lacking aP2. Endocrinology 141:3388-3396. https://doi.org/10.1210/ endo.141.9.7637

56. Maeda K, Cao H, Kono K et al (2005) Adipocyte/macrophage fatty acid binding proteins control integrated metabolic responses in obesity and diabetes. Cell Metab 1:107-119. https://doi. org/10.1016/j.cmet.2004.12.008

57. Mosińska P, Martin-Ruiz M, Gonzalez A et al (2019) Changes in the diet composition of fatty acids and fibre affect the lower gastrointestinal motility but have no impact on cardiovascular parameters: in vivo and in vitro studies. Neurogastroenterol Motil 30:e13651. https://doi.org/10.1111/nmo.13651

58. Feltrin KL, Little TJ, Meyer JH et al (2004) Effects of intraduodenal fatty acids on appetite, antropyloroduodenal motility, and plasma CCK and GLP-1 in humans vary with their chain length. Am J Physiol Integr Comp Physiol 287:R524-R533. https://doi. org/10.1152/ajpregu.00039.2004

59. Feltrin KL, Little TJ, Meyer JH et al (2008) Comparative effects of intraduodenal infusions of lauric and oleic acids on antropyloroduodenal motility, plasma cholecystokinin and peptide YY, appetite, and energy intake in healthy men. Am J Clin Nutr 87(5):1181-1187. https://doi.org/10.1093/ajcn/87.5.1181

60. Tadesse WT, Hailu AE, Gurmu AE, Mechesso AF (2014) Experimental assessment of antidiarrheal and antisecretory activity of $80 \%$ methanolic leaf extract of Zehneria scabra in mice. BMC Complement Altern Med 14:460. https://doi. org/10.1186/1472-6882-14-460

61. Accarino AM, Azpiroz F, Malagelada J-R (2002) Gut perception in humans is modulated by interacting gut stimuli. Am J Physiol Gastrointest Liver Physiol 282:220-225. https://doi.org/10.1152/ ajpgi.00161.2001.-Digestive

62. Hammer J, Führer M (2007) Intestinal chemo- and mechanosensitivity: selective modification of small intestinal sensitivity by lipids. Aliment Pharmacol Ther 26:117-124. https://doi.org/1 0.1111/j.1365-2036.2007.03352.x

63. Feinle-Bisset C, Azpiroz F (2013) Dietary lipids and functional gastrointestinal disorders. Am J Gastroenterol 108:737-747. https ://doi.org/10.1038/ajg.2013.76

64. Azain MJ (2004) Role of fatty acids in adipocyte growth and development. J Anim Sci 82:916-924. https://doi. org/10.2527/2004.823916x

65. Furuhashi M, Hiramitsu S, Mita T et al (2016) Reduction of circulating FABP4 level by treatment with omega-3 fatty acid ethyl esters. Lipids Health Dis 15:1-9. https://doi.org/10.1186/s1294 4-016-0177-8

66. Prostek A, Gajewska M, Bałasińska B (2016) The influence of eicosapentaenoic acid and docosahexaenoic acid on expression of genes connected with metabolism and secretory functions of ageing 3T3-L1 adipocytes. Prostaglandins Other Lipid Mediat 125:48-56. https://doi.org/10.1016/j.prostaglandins.2016.04.002

67. Rabalert J, Munkong N, Parklak W et al (2016) Effects of coconut oil on lipid accumulation in 3T3-L1 cells. Planta Med 82(S01):S1-S381. https://doi.org/10.1055/s-0036-1596845

68. Satory DL, Smith SB (1999) Conjugated linoleic acid inhibits proliferation but stimulates lipid filling of murine 3T3-L1 preadipocytes. J Nutr 129:92-97. https://doi.org/10.1093/jn/129.1.92

69. Li Y, Rong Y, Bao L et al (2017) Suppression of adipocyte differentiation and lipid accumulation by stearidonic acid (SDA) in 3T3-L1 cells. Lipids Health Dis 16(1):181. https://doi. org/10.1186/s12944-017-0574-7 